\title{
Modeling the Interaction of Milking Frequency and Nutrition on Mammary Gland Growth and Lactation
}

\author{
I. Vetharaniam*, S. R. Davis*, T. K. Soboleva*, \\ P. R. Shorten*, and G. C. Wake† \\ ${ }^{*}$ AgResearch Limited, Private Bag 3123 \\ Hamilton, New Zealand \\ †Department of Mathematics \& Statistics \\ University of Canterbury, Private Bag 4800 \\ Christchurch 1, New Zealand
}

\section{ABSTRACT}

A mathematical model of biological mechanisms regulating lactation is constructed. In particular, the model allows prediction of the effect of milking frequency on milk yield and mammary regression, and the interaction of nutrition and milking frequency in determining yield. Possible interactions of nutrition with milking frequency on alveolar dynamics are highlighted.

The model is based upon the association of prolonged engorgement (as a consequence of milk accumulation) of active secretory alveoli with changes in gene expression that result in impairment and, ultimately, cessation of milk secretion. The emptying of alveoli at milking, following alveolar contraction induced by oxytocin, prevents this process and also allows quiescent alveoli to reactivate. Prolonged engorgement results in apoptosis of the secretory cells and, hence, regression of the mammary gland. Milk yield is linked to alveolar populations, with secretion rates being modulated by nutrition and udder fill effects.

The model was used to investigate different management scenarios, and is in agreement with experimental results. The model shows that while milking frequency drives alveolar population, and therefore potential milk production, actual production varies considerably with nutrition. A significant portion of the loss associated with once-daily milking was due to udder fill rather than loss of secretory tissue. The model showed qualitative agreement with experimental data, on the acute and chronic effects of temporary once-daily milking.

(Key words: mammary gland, modeling, milking frequency, nutrition)

Received July 4, 2002.

Accepted November 4, 2002.

Corresponding author: Indrakumar Vetharaniam; e-mail: kumar. vetharaniam@agresearch.co.nz.
Abbreviation key: 1DM, 2DM, 3DM, 4DM = once-, twice-, thrice-, and four times daily milking; LA, HA = low and high allowance.

\section{INTRODUCTION}

There are marked differences in the shape of the lactation curve both within and between species. In the dairy cow, the curve is characterized by a rise in production from calving to peak production between 6 and 12 wk postpartum and then a steady decline in production of about 4 to $10 \%$ per mo, the rate of decline depending, in part, on variables such as nutrition, milking frequency and pregnancy (McFadden, 1996; Stelwagen, 2001).

The effect of changes in milking frequency on milk yield varies widely between individuals (Davis et al., 1999). Reducing milking frequency from twice daily milking (2DM) to once-daily milking (1DM) decreased milk yield from 7 to $34 \%$ and increased the rate of loss of udder tissue (Carruthers et al., 1993). Increasing milking frequency from 2DM to thrice-daily (3DM) increased milk yield by 7 to $20 \%$ (Stelwagen, 2001). Increased milking frequency has the potential to increase the persistency of lactation although, in practice, this may not be realized (Knight and Wilde, 1993).

While many models of the lactation curve have been formulated (for reviews, see Masselin et al., 1987; Beever et al., 1991), there is only limited published work which models the effect of milking frequency on lactation.

Neal and Thornley (1983) constructed a mathematical model which included the response of the udder to milking frequency, addressing both yield and mammary growth from parturition onwards. In this model, the mammary gland was assumed to consist of a single pool of active, secretory cells, whose death rate and milk secretion rate were assumed to decline continuously with milk accumulation. Despite reasonable performance of the model, it was not widely adopted because of tractability issues (Dijkstra et al., 1997). Fur- 
ther, Williams (1993) noted that the mechanisms that underpinned the model were not understood at the time.

The observations made by Molenaar et al. (1992) made possible the addition of a new dimension to a model of lactation. These authors showed that the secretory cell population within the udder consisted of alveoli in both active (secretory) and quiescent (engorged) states.

The engorged state of the quiescent alveoli indicated that they had once been secretory and the relatively high incidence of apoptotic cells in these quiescent areas suggested a higher rate of secretory cell regression in these alveoli (Molenaar et al., 1996). This will result in two pools of cells: those undergoing apoptosis and a residual pool of dedifferentiated cells. Since the dedifferentiated cells no longer contribute to lactation, they are considered together with senescent cells as a loss of secretory tissue. Further, experiments which demonstrated substantial recovery of milk yield $12 \mathrm{~d}$ after cessation of milking (and mammary engorgement) provided evidence that quiescent cells can revert to an active, secretory state-if the engorgement can be relieved (Hamann and Reichmuth, 1990).

Davis et al. (1999) linked the mechanisms that regulate the switching of an alveolus between active and quiescent states to deformation of its constituent secretory cells as a consequence of engorgement. Additionally, Davis et al. (1999) proposed that all secretory cells in the udder must pass through this quiescent stage before undergoing apoptosis (senescence). These ideas were presented in mathematical form by Shorten et al. (2002). Increasing milking frequency increased the number of active alveoli by reducing rates of quiescence and senescence, and enhancing the reactivation of quiescent alveoli.

While the number of active alveoli (and hence the number of actively secreting cells) has an impact on milk yield, nutrition too has a strong mediating influence which needs to be taken into account in a model of lactation.

This paper combines the alveolar model given by Shorten et al. (2002) with an animal model (Vetharaniam et al., 2001) to produce a lactation model that is sensitive to both intake and milking frequency. Results from model simulations to investigate the interactions of nutrition and milking frequency are discussed. Additionally, the biology and motivation underpinning the alveolar model are discussed.

\section{MATERIALS AND METHODS}

\section{Schema of Lactation Model}

The model comprises an energy pool, $N$, (in MJ) supplying energy to the mammary gland whose secretory cells are divided into numbers of active (secreting) alveoli, $A$, and quiescent alveoli, $Q$, and a pool of milk, $v$, (in liters), which is the combined accumulation of milk in the alveoli and the cistern (Figure 1). In the alveolar sub-model, division of progenitor cells at a rate $r_{p a}$ provides a source of new alveoli for the active pool, active alveoli become quiescent at rate $r_{a q}$, and quiescent alveoli return to the active state at rate $r_{q a}$; additionally, there is a permanent loss of alveoli from the mammary gland as quiescent alveoli become senescent at a rate $r_{q s}$ (Figure 1). Molenaar et al. (1992) observed the presence of such pools in bovine and ovine mammary tissue by in situ hybridization studies. In biopsied mammary tissue from lactating dairy cows approximately $10 \%$ of alveoli appeared to be quiescent (Farr et al., 1996).

Milk secreted by the active alveoli at a rate $r_{s}$ (liters/ day), adds to the milk pool, while milk is lost at a rate $r_{h}$ (liters/day) through harvest at discrete milking events (Figure 1).

The energy pool corresponds to the blood-energy flux of the cow, and is used to modulate milk yield. It provides both the energy contained in the milk and the energy required to drive biochemical changes associated with lactation; it also provides for growth and pregnancy, and this allows for competition between different energy uses. The model imposes an energy cost of $0.25 \mathrm{MJ}$ of heat for each MJ of milk produced $(80 \%$ efficiency) and a $10 \%$ increase in metabolic rate (maintenance) during lactation. The level of the energy pool will change with energy intake and energy flows to lactation and other uses such as growth and pregnancy. The dynamics of the energy pool, $N$, are developed in Vetharaniam et al. (2001), and in this paper we concentrate on the dynamics of $v, A$, and $Q$.

Let $t$ be the time (days) from parturition. The evolution with time of $v, A$ and $Q$ in Figure 1 are given by the following set of differential equations:

$$
\begin{gathered}
\frac{\mathrm{d} v}{\mathrm{~d} t} \equiv r_{s}-r_{h} \\
\frac{\mathrm{d} A}{\mathrm{~d} t} \equiv r_{p a}-r_{a q}+r_{q a} \\
\frac{\mathrm{d} Q}{\mathrm{~d} t} \equiv r_{a q}-r_{q a}-r_{q s}
\end{gathered}
$$

In the rest of this section mathematical expressions are given for the quantities on the right hand side of Equations 1 to 3.

\section{Milk Secretion and Harvest}

In the model, milk secretion is dependent on the number of active (secreting) alveoli, the level of the energy 


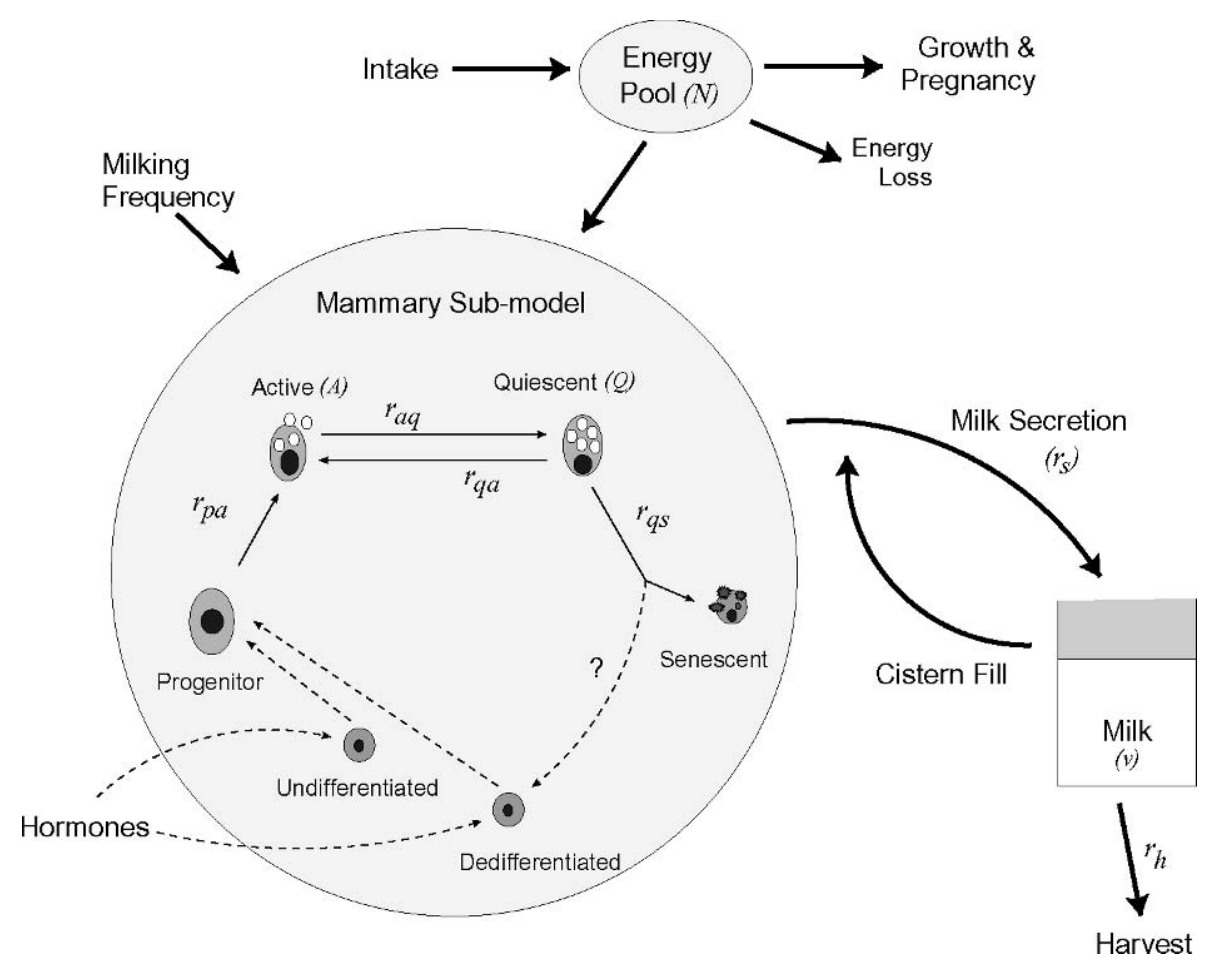

Figure 1. Schema of the lactation model, with secretory cells divided into numbers of active and quiescent alveoli. The dashed lines in the mammary submodel are not represented explicitly in the model.

pool, and also the degree of fullness of the udder. Figure 2 shows the distribution of milk in the udder over time since the last milking. Initially, secreted milk is contained primarily in the alveoli. As the pressure in engorged alveoli overcomes the resistance of the small

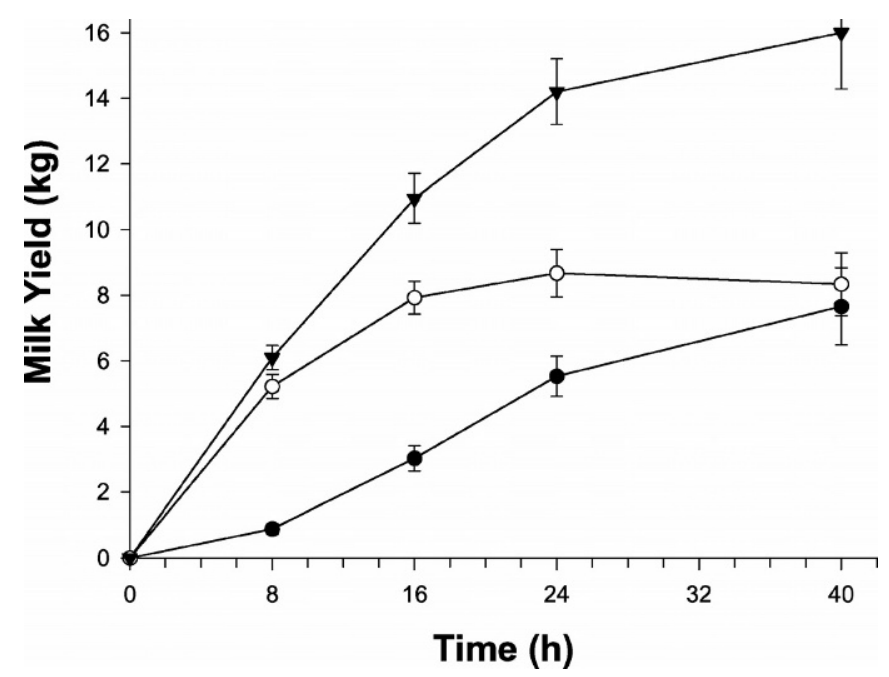

Figure 2. Distribution of milk in udder with time since last milking: $\bigcirc$-alveolar, $\mathbf{0}$-cisternal, $\boldsymbol{\nabla}$-total. (Reproduced from Davis et al., 1998). ducts, milk "leaks" into the larger ducts and drains into the cistern. Columns of milk build up in the ducts, and eventually the secretion of all alveoli is curtailed by the increase in hydrostatic pressure.

The energy pool, $N$ is postulated to have an upper limit, $N_{u}$ (Vetharaniam et al., 2001). For the case when the udder is not sufficiently full to impair milk secretion, Davis et al. (2001) expressed the milk secretion rate of the "average" alveolus, in $\mathrm{MJ} /$ day, as $S_{\max }(N /$ $\left.N_{u}\right)^{L}$, where $S_{\max }$ is the maximum possible secretion rate of an alveolus (in $\mathrm{MJ} / \mathrm{d}$ ), $N / N_{u}$ is a measure of the energetic status of the animal, and $L$ is a genetic parameter that governs the degree to which secretion rate is buffered during nutritional stress. The above expression for secretion can be modified to account for the effect of milk, $v$, in the udder, and to express it in terms of liters/day:

$$
r_{s}=S_{\max } / \rho_{\operatorname{milk}}\left(\frac{N}{N_{u}}\right)^{L}\left(1-\left(\frac{v}{v_{u}}\right)^{c}\right)
$$

where $\rho_{\text {milk }}$ is the energy density of milk (MJ/), $v_{u}$ (liters) is the capacity of the udder for storage, and $c$ (dimensionless) is a parameter that governs the rate at which the secretion rate declines as $v$ increases. Most of the time, secretion will be unimpaired, but as $v$ nears 
$v_{u}$, secretion will start to slow down, and eventually stop. $v_{u}$ has cisternal and alveolar contributions:

$$
v_{u}=v_{a}(A+Q)+v_{c},
$$

where $v_{a}$ (liters) is the average capacity of an alveolus and $v_{c}$ (liters) is the volume of the cistern and large ducts, assumed constant throughout the lactation. It should be noted that breeds of cow vary considerably in the quantity of milk which can be accumulated in the udder. US Holsteins on high quality, spring pasture fill their udders to capacity approximately $20 \mathrm{~h}$ post milking (Davis, S. R. and Kolver, E. R.; Unpublished), whereas pasture-fed New Zealand Jersey cows continue to accumulate milk for more than $26 \mathrm{~h}$ (Davis et al., 1999). US Holsteins on concentrate diets fill their udders to capacity after 18 hours (Davis et al., 1999). Thus $v_{u}$ can obviously be of critical importance to the degree of production loss with 1DM.

The harvesting of milk occurs at distinct events (each milking time) and this can be modeled using a delta $(\delta)$ function (a mathematical "spike"). If $T_{i}$ (in days since parturition) is the time of milking for each milking $i$, the rate of milk removal is given by

$$
r_{h}=\sum_{i=1}^{m} \delta\left(t-T_{i}\right) v .
$$

$\delta\left(t-T_{i}\right)$ can be thought of as the limit of a normal distribution with mean $t-T_{i}$, as its standard deviation tends to zero. It is assumed that all milk is removed from the udder, although in practice there is some residual milk after each milking, which is typically in the order of 5 to 14\% (Carruthers et al., 1993; Isaakson and Arnarp, 1998). From a modeling point of view, the effect of residual milk is to reduce effective udder volume.

\section{Alveolar Function and Response to Milking Frequency}

Richardson (1947) noted that alveolar distension in goats arising from milk accumulation resulted in substantial deformation of secretory cells, and Peaker (1980) suggested this was likely to be the trigger for involution of the mammary gland at the end of lactation. Davis et al. (1999) proposed a mechanism whereby changes in mammary function were initiated by changes in cell shape through alveolar filling. The proposed mechanisms are reflected in the functional forms for the rates in Equations 2 and 3, and each of these rates is addressed in turn.

\section{Rate of Generation of Alveoli}

The majority of the alveoli are assumed to have been established during pregnancy, and these undergo lacto- genesis around parturition. However, following previous authors (Neal and Thornley, 1983; Dijkstra et al., 1997), it is assumed that there is a pool of cells which differentiate to contribute new active alveoli during early lactation at a rate $r_{p a}$. This differentiation may or may not be accompanied by cell division. Evidence for cell division occurring in mammary epithelium has been obtained via demonstrations of mitotic figures in the bovine mammary epithelium in early lactation (Franke and Keenan, 1979). Further, mammary DNA in the bovine udder was maintained from early, through to peak, lactation (Davis, S. R., unpublished data) but declined thereafter. For present purposes, this maintenance of DNA is assumed to be via the development of functional alveoli, but could also arise from increased cell numbers in existing alveoli.

There may be no net gain in secretory tissue unless particular treatments (such as very frequent milking) are applied (Bar-Peled et al., 1995). The same functional form used by Dijkstra et al. (1997) for $r_{p a}$ is adopted:

$$
r_{p a}=k_{1} \exp \left(-k_{2} t\right)
$$

where $k_{1}$ (a constant with units day ${ }^{-1}$ ) is the rate of proliferation of alveoli at parturition $(t=0)$, and $k_{2}$ (constant with units day ${ }^{-1}$ ) governs the rate at which this source term decays.

\section{Rate of Quiescence of Active Alveoli}

An alveolus typically consists of 150 to 300 secretory cells (Weber et al., 1955) emptying via a narrow duct which provides a resistance to milk flow. As a result, the alveolus will accumulate secretion and become engorged, deforming the secretory cells. Davis et al. (1999) hypothesized that this deformation leads to changes in gene expression and quiescence of the cells, unless milk ejection intervenes and the alveolus is emptied. There are several examples of genes in the rodent mammary gland which appear to be switched on or off within a few hours of milk accumulation (Nguyen and Pollard, 2000).

There are several phases in the response to alveolar milk accumulation after an alveolus was last emptied (Davis et al., 1999). All alveoli in the bovine udder are full at about $16 \mathrm{~h}$ postmilking (Davis et al., 1998). There is also evidence of a mild inflammatory response beginning around $14 \mathrm{~h}$ postmilking, ultimately exhibited by the breakdown of tight junctions between epithelial cells, allowing mixing of milk with extracellular fluid (Stelwagen et al., 1995b). Breakdown of tight junctions is, in itself, associated with reduced milk secretion (Stelwagen et al., 1995a). 
Rate of quiescence

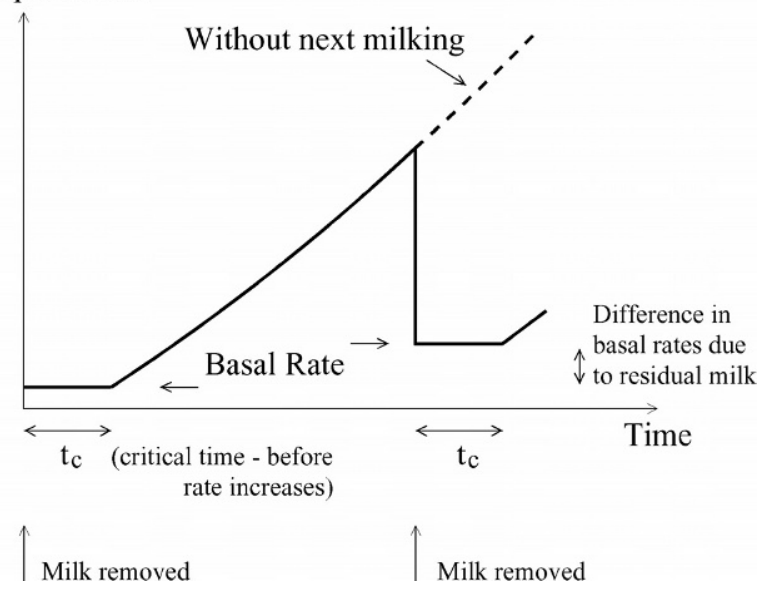

Figure 3. The rate of quiescence of active alveoli increases in a nonlinear fashion with time.

During normal milking routines, residual milk is retained in the secretory parenchyma, resulting in quiescence of alveoli even after milking. The rate of quiescence, $r_{a q}$ is assumed to be small for a "critical" time, $t_{c}$, after milking. After the time $t_{c}$ has elapsed, $r_{a q}$ gets larger as alveoli which were emptied become engorged. Milking interrupts this process, and reduces $r_{a q}$ to a small value.

This behavior is shown in Figure 3 and can be expressed mathematically as

$$
\begin{gathered}
r_{a q}=\sum_{i=0}^{m}\left[p_{b}+\left(t-T_{i}-t_{c}\right) k u\left(t-T_{i}-t_{c}\right)\right] A\left[u\left(t-T_{i}\right)\right. \\
\left.-u\left(t-T_{i+1}\right)\right],
\end{gathered}
$$

where $p_{b}$ (units day ${ }^{-1}$ ) is the rate of quiescence immediately after milking, and depends on the quantity and distribution of residual milk, $T_{0}=0$ days is the beginning of lactation, $T_{i}(i=1, \ldots, m)$ are the times (in days) at which milkings occur, and $k$ (units day $^{-2}$ ) reflects the increase in the rate of quiescence $t_{c}$ after the last milking. The function $u$ is the unit step function, which acts like a switch:

$$
u(t)=\left\{\begin{array}{l}
0, t<0 \\
1, t \geq 0
\end{array}\right.
$$

\section{Rate of Reactivation of Quiescent Alveoli}

Davis et al. (1999) hypothesized that the changes in gene expression that induce the quiescence of active alveoli occur in response to alveolar distension. Emptying of alveoli can reactivate their milk synthesis and secretion. This emptying occurs in well-defined pulses, coincident with each milking time. However, there is a delay before reactivation, and each emptied quiescent alveolus will have a different time delay, depending on how long it has been quiescent (Farr et al., 1998). Thus, the arrival of reactivated alveoli into the active pool is temporally distributed and lags the milking times. The nature of this distribution is not known, and for the purpose of simplification, the variance in reactivation time is ignored. Furthermore, Shorten et al. (2002) show that the lag between emptying and reactivation can be ignored, and thus the appearance in pool $A$ of reactivated alveoli is modeled as a pulse arriving at the same time as they were emptied. This justifies the use of the same rate, $r_{q a}$ in Equations 2 and 3. A pulse can be modeled using the delta function in Equation 6:

$$
r_{q a}=\sum_{i=1}^{m} p_{e} \delta\left(t-T_{i}\right) Q
$$

where $p_{e}$ (unitless) is the fraction of quiescent alveoli emptied at each milking, $i$, at time $T_{i}$ for $i=1, \ldots, m$. $p_{e}$ can be considered as the probability of an alveolus being emptied at milking $i$.

\section{Rate of Senescence of Quiescent Alveoli}

The changes in cell gene expression caused by the engorgement of an alveolus initiate a pathway that eventually leads to apoptosis unless this pathway is interrupted following emptying of an alveolus and its subsequent reactivation.

An alveolus will stay in a quiescent state for a finite time before apoptosis (or dedifferentiation) of its constituent cells is initiated (after which it cannot be rescued and will regress). This "duration of quiescence" might be expected to vary between alveoli, just as it would between cells. The biology results in a rather complex expression for the rate of senescence, $r_{q s}$, and this is discussed in the appendix. Numerical evaluation of the equation is costly in terms of computation time, and furthermore requires past values of $r_{a q}$ (the rate of quiescence) to be stored. However, the simplification,

$$
r_{q s}=k_{5} Q,
$$

can be used for $r_{q s}$ (Shorten et al., 2002), where $k_{5}$ has units of day ${ }^{-1}$.

\section{RESULTS}

\section{Model Calibration}

Results from a study of New Zealand Holstein-Friesians grazing pasture (Vetharaniam et al., Unpublished), 
Table 1. Parameter values used for simulations.

\begin{tabular}{|c|c|c|c|c|c|}
\hline Parameter & Value & (SE) & Scale & Units & Equation \\
\hline$A_{0}$ & $2.19^{3}$ & $(0.11)$ & $\times 10^{10}$ & & Initial value \\
\hline$L$ & $7.29^{3}$ & $(0.67)$ & $\times 10^{-1}$ & & $(4)$ \\
\hline$S_{\max }$ & $3^{1}$ & & $\times 10^{-9}$ & MJ day ${ }^{-1}$ & (4) \\
\hline$\rho_{\text {milk }}$ & $3.1^{2}$ & & & $\mathrm{MJ} \mathrm{l^{-1 }}$ & (4) \\
\hline$c$ & $8.5^{4}$ & & & & (4) \\
\hline$k$ & $4.55^{3}$ & & $\times 10^{-2}$ & day $^{-2}$ & (8) \\
\hline$k_{1}$ & $2.16^{3}$ & $(0.16)$ & $\times 10^{9}$ & day $^{-1}$ & (7) \\
\hline$k_{2}$ & $3.55^{3}$ & $(0.45)$ & $\times 10^{-1}$ & day $^{-1}$ & (7) \\
\hline$k_{5}$ & $4.37^{3}$ & $(0.45)$ & $\times 10^{-2}$ & day $^{-1}$ & (11) \\
\hline$p_{b}$ & $1.11^{3}$ & & $\times 10^{-1}$ & day $^{-1}$ & (8) \\
\hline$p_{e}$ & $7.11^{3}$ & & $\times 10^{-1}$ & & (10) \\
\hline$t_{c}$ & $2.07^{3}$ & & $\times 10^{-1}$ & days & (7) \\
\hline$v_{a}$ & $4^{4}$ & & $\times 10^{-10}$ & liters & (5) \\
\hline$v_{c}$ & $7.6^{4}$ & & & liters & (5) \\
\hline
\end{tabular}

were used to generate daily profiles for active and quiescent alveoli, for 2DM, over a whole lactation. Equations 2 and 3, together with Equations 7, 8, 10, and 11 were then calibrated to these profiles.

Since the parameters $p_{b}, k$, and $t_{c}$ all contribute to the rate $r_{a q}$ (Equation 10), in order to produce a unique fit for these parameters, data for several different milking frequencies are required. Despite the absence of such data, the model fit can be used to investigate the sensitivity of the model. Assumptions made in performing the calibration were that $A_{0}$, the population of active alveoli at $t=0$, is nonzero, and that the initial population of quiescent alveoli is zero. Values for $S_{\max }$ and $\rho_{\text {milk }}$ were obtained from literature. The estimated value for $c$ was 8.5 , which corresponds to a 10 to $15 \%$ decrease in secretion when the udder is 85 to $90 \%$ full at $24 \mathrm{~h}$ (Davis et al., 1998); $v_{c}$ was estimated to be 7.6 $\mathrm{L}$ (Davis et al., 1998); $v_{a}$ was estimated as $0.4 \mathrm{nl}$, based on 25 to $35 \mathrm{~g}$ of secretory cell DNA during mid lactation, $6 \mathrm{pg}$ of DNA per cell, and total alveolar capacity of 8.4 L (Davis et al., 1998). Table 1 summarizes these parameter values.

In the simulations, cows were offered either a low or high pasture allowance, specified in terms of $\mathrm{kg}$ of dry matter (DM), and pasture quality (MJ/kg DM) was assumed the same for both allowance levels (see Figure 4). The low allowance (LA) was based on data for Jerseycross cows from Hutton (1963), scaled to reflect intakes by Friesians. The high allowance (HA) was $20 \%$ higher than LA until $150 \mathrm{~d}$ into lactation, then maintained near this level, while the LA declined. Pasture quality was also based on data cited by Hutton (1963).

The cow model used in the simulation generates an intake demand which reflects the physiological status of the cow. In the simulation it was assumed that a cow would not eat more than its demand, even if its allowance was higher. Partitioning of energy between pregnancy, growth and lactation is mediated through a blood-energy-flux pool and the energy status (degree to which the cow is well-fed). Only the results pertaining to lactation are presented here, and are for barren cows. The effect of pregnancy is discussed below.

\section{Model Predictions}

Milk production increased with milking frequency for both allowance levels, although a greater response was shown with the HA (Figure 5). Where the curves for HA and LA, for any given milking frequency, coincide, the cow's energy demands are being met by either allowance, indicating secretion is at a maximum during that time. With $1 \mathrm{DM}$ this occurs from $70 \mathrm{~d}$ postpartum until drying off, whereas with four milkings a day (4DM), this occurs briefly around 140 days postpartum, re-

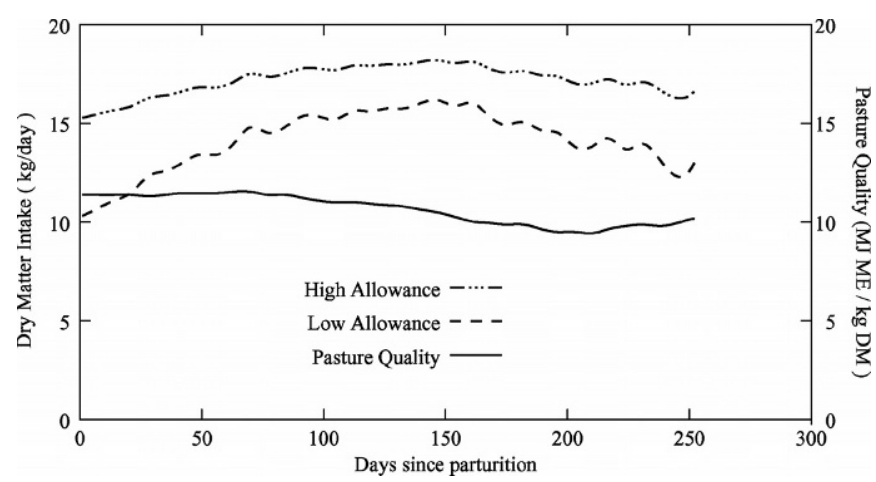

Figure 4. Dry matter allowance and pasture quality in the simulation over the lactation. 


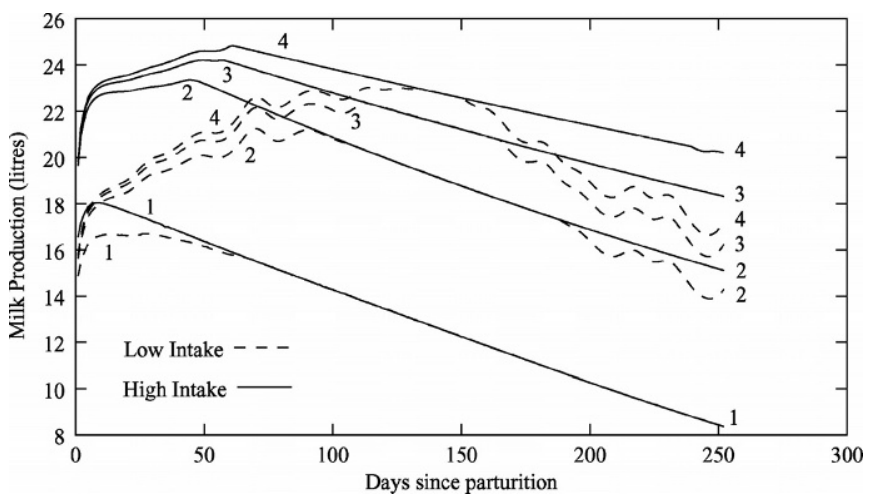

Figure 5. Predicted daily milk production over the lactation, for two different dry matter allowance levels, for four different milking frequencies.

flecting the greater demand for energy with increased milking frequency. This is illustrated by Figure 6, which shows the energy status of the cow under each treatment. With HA, cows are at a $100 \%$ energy status (fed maximally and producing at maximum) for most of the lactation. However, with LA, the increased metabolic demand associated with increased milking frequency results in lower energy balances.

Both the number of alveoli and the secretion rate act to determine milk production. Multiplying active alveoli populations by secretion rate, $S$, gives an upper limit to milk production. However the actual production curves (Figure 5) do not show the same shape as the corresponding curves for active alveoli (Figure 7) because secretion rate (Equation 4) varies with energy status (Figure 6).

The peak population of alveoli occurs very early in lactation, when energy status is low, and thus potential production is not reached at that time. Peak production

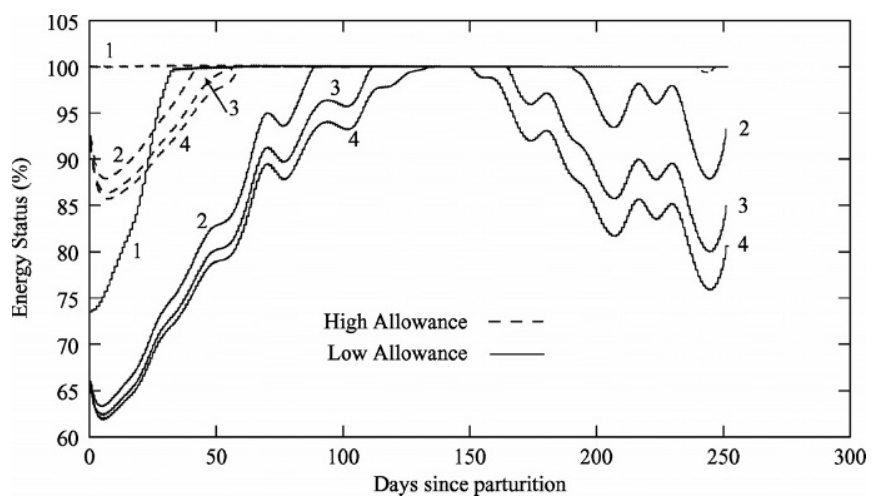

Figure 6. Predicted energy status of the cow over the lactation, for two different dry matter allowance levels, for four different milking frequencies, with $100 \%$ energy status corresponding to fully fed.

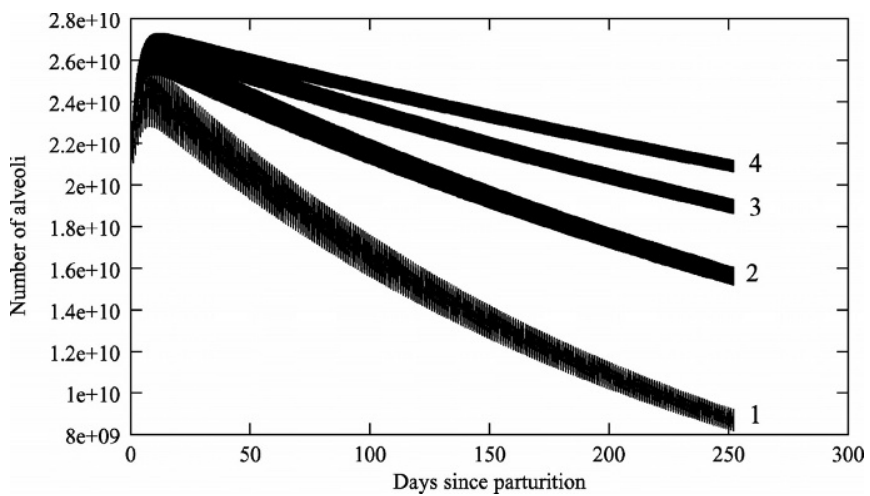

Figure 7. Predicted active alveoli populations over the lactation for four different milking frequencies.

occurs when energy status has risen, considerably after the peak population of alveoli occurs, with the time lag depending on both milking frequency and allowance level.

Production statistics are presented in Table 2.

$1 D M$ resulted in production losses of $29 \%$ on LA and $33 \%$ on HA, compared with 2DM. 3DM and $4 \mathrm{DM}$ increased production over $2 \mathrm{DM}$ by $8 \%$ and $12 \%$ respectively on LA, and $10 \%$ and $16 \%$ on HA. At the end of lactation, 1DM resulted in $44 \%$ lower numbers of alveoli than with $2 \mathrm{DM}$, while $3 \mathrm{DM}$ and $4 \mathrm{DM}$ respectively gave increases in alveoli of $22 \%$ and $40 \%$ when compared with 2DM.

Differences between alveolar populations for 1DM and higher milking frequencies were small during early lactation compared with the differences in yield during the same period. Two ways of ameliorating fill effects were considered: either increasing the cistern capacity of the udder, or increasing the energy/solids content of milk, so that less volume of milk is produced for the same milk energy. Increasing cistern capacity by $20 \%$ only reduced this loss by $1 \%$ on HA. However, increasing the solids' content of milk by $20 \%$ reduced the loss in total yield associated with $1 \mathrm{DM}$ by $5 \%$ on HA and by $4 \%$ on LA (Table 3 ). On HA, loss in peak yield was reduced by $10 \%$.

Rémond et al. (1999) investigated the effect of temporary $1 \mathrm{DM}$ on milk production. They found that primiparous cows subject to $1 \mathrm{DM}$ for the first $3 \mathrm{wk}$ of lactation, followed by $2 \mathrm{DM}$, suffered a $21 \%$ loss in production in the first $3 \mathrm{wk}$, with a long term loss (9\% in wk 13 to 18), despite the resumption of $2 \mathrm{DM}$ from wk 4 onwards. In a simulation of that experiment using the model, $1 \mathrm{DM}$ for the first $3 \mathrm{wk}$ of lactation resulted in a production loss of $21 \%$, compared with 2DM, on HA, but with LA, this production loss was only $8 \%$. By wk 13 to 18 , there was a long term loss in mammary tissue of $4 \%$, 
Table 2. Predictions for milk yield and alveoli populations.

\begin{tabular}{|c|c|c|c|c|c|c|c|c|c|c|}
\hline \multirow[b]{3}{*}{ Freq. } & \multicolumn{6}{|c|}{ Milk yield (liters) } & \multicolumn{4}{|c|}{ Alveoli $\left(\times 10^{10}\right)$} \\
\hline & \multicolumn{3}{|c|}{ Low allowance } & \multicolumn{3}{|c|}{ High allowance } & \multicolumn{2}{|c|}{ Active } & \multicolumn{2}{|c|}{ Quiescent } \\
\hline & Total & Peak & Final & Total & Peak & Final & Peak & Final & Peak & Final \\
\hline 1 & 3290 & 16.7 & 8.4 & 3340 & 18.0 & 8.4 & 2.57 & 0.87 & 0.41 & 0.10 \\
\hline 2 & 4650 & 21.2 & 14.3 & 4950 & 23.3 & 15.1 & 2.67 & 1.56 & 0.21 & 0.08 \\
\hline 3 & 5020 & 22.3 & 16.2 & 5460 & 24.2 & 18.3 & 2.71 & 1.90 & 0.14 & 0.06 \\
\hline 4 & 5200 & 23.0 & 17.2 & 5740 & 24.8 & 20.2 & 2.73 & 2.09 & 0.10 & 0.05 \\
\hline
\end{tabular}

and a loss in production of the same amount for either allowance (Table 4).

While peak numbers of active alveoli and numbers of active alveoli at the end of the lactation increased with milking frequency, for quiescent alveoli this pattern was reversed (Table 2). Thus increased milking frequency results in a greater proportion of alveoli in an active state.

Qualitatively the model behavior agreed with the experimental evidence, although predicted long-term losses in milk yield were half of what was measured. Larger long-term losses can be obtained from the model by increasing the parameter $k_{5}$, which governs the rate of senescence. The long-term loss in milk yield is associated with mammary tissue loss, whereas the majority of the loss in the first three weeks is due to udder fill limiting secretion. This is why the effect is less pronounced with LA for which secretion rates are reduced.

A $20 \%$ increase in cistern capacity of the udder reduced production loss in the first three weeks by $3 \%$ for HA.

The simulations were rerun with all cows mated on d 80 of lactation. Pregnancy had a neglible effect on total milk production over the 250-d lactation, for all treatments, and did not affect the lactation curves of cows on HA. Pregnancy had no effect on LA cows early in lactation. For pregnant LA cows milked between 2 and 4 times per $\mathrm{d}$, yield was supressed by an average of $0.1 \mathrm{~L} / \mathrm{d}$ on d 120 of pregnancy (d 200 of lactation), and by an average of $0.5 \mathrm{~L} / \mathrm{d}(3 \%)$ on $\mathrm{d} 170$ of pregnancy (d 250 of lactation).

\section{DISCUSSION}

This paper presents a mechanistic mathematical model of the response of the mammary gland to milking frequency, based on mechanisms presented by Davis et al. (1999). These mechanisms are proposed to be the result of changes in gene expression of secretory cells, caused by cell deformation through the engorgement of alveoli. There are several reports, from rodent studies, that changes in mammary gene expression are early events during milk accumulation (e.g., Nguyen and Pollard, 2000).

Alternative mechanisms for the regression of the mammary gland exist, such as FIL (feedback inhibitor of lactation: Peaker and Wilde, 1996) or a $\beta$-casein breakdown product (Silanikove et al., 2000). Since FIL is postulated to act only when a cell is engorged (Stelwagen, 2001), the model construction is consistent with the existence of FIL.

The model suggests that the size of the quiescent pool of alveoli is small relative to the active pool, but that small shifts in this population are associated with substantial changes in secretory capacity over time. Thus increased milking frequency will result in increased persistency of lactation unless nutritional constraints intervene (see Stelwagen, 2001).

The model combines the effect of nutrition on milk secretion with a mathematical expression of the mechanisms by which milking frequency affects mammary gland growth. It provides the capability to predict the lactational performance of a cow under different nutritional and milking regimes. Model predictions for milk production are in agreement with experimentally observed results reported in the literature. Thus the model is useful for investigating different nutritional and management scenarios, for both teaching and research purposes.

Several of the parameters in the model have the potential to show diet and or genotype effects which could be useful for selection purposes.

Table 3. Effect of milk energy concentration on production loss of once daily milking compared with twice daily milking.

\begin{tabular}{llllll}
\hline & \multicolumn{2}{c}{ Low allowance } & & \multicolumn{2}{c}{ High allowance } \\
\cline { 2 - 3 } \cline { 5 - 6 } Energy density of milk & $3.7 \mathrm{MJ} / 1$ & $3.1 \mathrm{MJ} / \mathrm{l}$ & & $3.7 \mathrm{MJ} / \mathrm{l}$ & $3.1 \mathrm{MJ} / \mathrm{l}$ \\
\hline Change in total yield & $-25 \%$ & $-29 \%$ & & $-28 \%$ & $-33 \%$ \\
Change in peak yield & $-17 \%$ & $-21 \%$ & & $-13 \%$ & $-23 \%$ \\
\hline
\end{tabular}


Table 4. Model predictions and experimental values (from Rémond et al., 1999) for yield loss in primiparous cows milked once daily for 3 wk and then twice daily, when compared with twice daily milking for the same period.

\begin{tabular}{lllc}
\hline & $\begin{array}{l}\text { Low } \\
\text { allowance }\end{array}$ & $\begin{array}{l}\text { High } \\
\text { allowance }\end{array}$ & $\begin{array}{l}\text { Rémond } \\
\text { et al. }\end{array}$ \\
\hline Wk 1 to 3 & $8 \%$ & $21 \%$ & $21 \%$ \\
Wk 4 to 6 & $3 \%$ & $3 \%$ & $5 \%$ \\
Wk 7 to 12 & $3 \%$ & $4 \%$ & $7 \%$ \\
Wk 13 to 18 & $4 \%$ & $4 \%$ & $9 \%$ \\
\hline
\end{tabular}

The parameter $L$, which was introduced in Equation 4 as a genetic parameter, governs the sensitivity of milk production to deficits in intake. Cows which have greater ability to maintain high production when under nutritional stress will have a lower value of $L$.

The parameter $p_{b}$ in Equation 8 corresponds to the fraction of active alveoli not emptied during milking, while $p_{e}$ in Equation 10 corresponds to the fraction of quiescent alveoli emptied (and reactivated) at each milking time. Since emptying of the alveoli at milking is controlled by oxytocin, these parameters may be related to plasma oxytocin concentration at milking or to sensitivity of alveoli to oxytocin, and both may be responsive to nutrition.

The term $t_{c}$ in Equation 8 reflects the time taken for an alveolus to engorge, which is strongly dependent on secretion rate. Thus one would expect a strong dependence of $t_{c}$ on nutrition.

The parameter $k$ in Equation 8 governs the increase in rate of quiescence after milking, while the parameter $k_{5}$ in Equation 13 governs the rate of senescence. Both of these parameters are related to how quickly secretory cells change their gene expression following alveolar engorgement, and have the potential to show both genotypic and nutritional effects.

A multifactorial trial which includes different diets, milking frequencies and genetics would more precisely indicate which of the parameters in the model show diet, genotypic, or genotype-diet effects. Such information would be valuable for selection purposes and, additionally, would allow further development of the model, for example to including milk composition.

\section{ACKNOWLEDGMENTS}

The authors thank A. B. Pleasants, M. Upsdell and S. J. R. Woodward for helpful discussions.

\section{REFERENCES}

Bar-Peled, U., E. Maltz, I. Bruckental, Y. Folman, Y. Kali, H. Gacitua, A. R. Lehrer, C. H. Knight, B. Robinson, H. Voet, and H. Tagari. 1995. Relationship between frequent milking or suckling in early lactation and milk production of high producing dairy cows. J. Dairy Sci. 78:2726-2736.
Beever, D. E., A. J. Rook, J. France, M. S. Dhanoa, and M. Gill. 1991. A review of empirical and mechanistic models of lactational performance by the dairy cow. Livest. Prod. Sci. 29:115-130.

Carruthers, V. R., S. R. Davis, A. Bryant, H. V. Henderson, C. A. Morris, and P. J. A. Copeman. 1993. Response of Jersey and Friesian cows to once a day milking and prediction of response based on udder characteristics and milk composition. J. Dairy Res. 60:1-11.

Davis, S. R., V. C. Farr, P. J. A. Copeman, V. R. Carruthers, C. H. Knight, and K. Stelwagen. 1998. Partitioning of milk accumulation between cisternal and alveolar compartments of the bovine udder: relationship to production loss during once daily milking. J. Dairy Res. 65:1-8.

Davis, S. R., V. C. Farr, and K. Stelwagen. 1999. Regulation of yield loss and milk composition during once-daily milking: a review. Livest. Prod. Sci. 59:77-94.

Davis, S. R., I. Vetharaniam, M. Upsdell, E. S. Kolver, and A. B. Pleasants. 2001. Modelling the impact of nutrition and genotype on lactation. Proc. N.Z. Soc. Anim. Prod. 61:237-238. Brief Communication.

Dijkstra, J., J. France, M. S. Dhanoa, J. A. Maas, M. D. Hanigan, A. J. Rook, and D. E. Beever. 1997. A model to describe growth patterns of the mammary gland during pregnancy and lactation. J. Dairy Sci. 80:2340-2354.

Farr, V. C., K. Stelwagen, L. R. Cate, A. J. Molenaar, T. B. McFadden, and S. R. Davis. 1996. An improved method for the routine biopsy of bovine mammary tissue. J. Dairy Sci. 79:543-549.

Farr, V. C., K. Stelwagen, and S. R. Davis. 1998. Rates of recovery of milk yield and composition following milking intervals of varying length. Proc. N.Z. Soc. Anim. Prod. 58:47-48.

Franke, W. W., and J. W. Keenan. 1979. Mitosis in milk secreting epithelial cells of mammary gland. Differentiation 13:81-88.

Hamann, J., and J. Reichmuth. 1990. Compensatory milk production within the bovine udder: effects of short-term milking of single quarters. J. Dairy Res. 57:17-22.

Holmes, C. W., and G. F. Wilson. 1984. Milk production from pasture. Butterworths, Wellington, N.Z.

Hutton, J. B. 1963. The effect of lactation on intake in the dairy cow. In: Proc. N.Z. Soc. Anim. Prod. 23:39-52.

Isaakson, A., and L. Arnarp. 1998. Quantitative estimation of residual milk in bovine udders-a methodological study. Acta Veterinaria Scandinavica 29:259-262.

Knight, C. H., and C. J. Wilde. 1993. Mammary cell changes during pregnancy and lactation. Livest. Prod. Sci. 35:3-19.

Masselin, S., D. Sauvant, P. Chapoutot, and D. Milan. 1987. Les modèles d'ajustement des courbes de lactation. Ann. Zootech 36:171-206.

McFadden, T. B. 1996. Prospects for improving lactational persistency. Pages 319-339 in Milk composition, production and biotechnology. R. A. S. Welch, D. J. W. Burns, S. R. Davis, A. I. Popay, and C. G. Prosser, eds. CAB International, New York.

Molenaar, A. J., S. R. Davis, and R. J. Wilkins. 1992. Expression of $\alpha$-lactalbumin, $\alpha$-S1-casein, and lactoferrin genes is heterogeneous in sheep and cattle mammary tissue. J. Histochem. Cytochem. 40(5):611-618.

Molenaar, A. J., R. J. Wilkins, and S. R. Davis. 1996. Measurement of cell death by in situ and labelling of ruminant mammary gland tissue. Proc. N.Z. Soc. Anim. Prod. 56:71-76.

Neal, H. D. S. C., and J. H. M. Thornley. 1983. The lactation curve in cattle: a mathematical model of the mammary gland. J. Agric. Sci. Camb. 101:389-400.

Nguyen, A. V., and J. W. Pollard. 2000. Transforming growth factor $\beta 3$ induces cell death during the first stage of mammary gland involution. Development 127:3107-3118.

Peaker, M. 1980. The effect of raised intramammary pressure on mammary function in the goat in relation to the cessation of lactation. J. Physiol. 301:415-428.

Peaker, M., and C. J. Wilde. 1996. Feedback control of milk secretion from milk. Journal of Mammary Gland Biology and Neoplasia 1(3):307-315.

Rémond, B., J.-B. Coulon, M. Nicloux, and D. Levieux. 1999. Effect of temporary once-daily milking in early lactation on milk produc- 
tion and nutritional status of dairy cows. Ann. Zootech. 48:341-352.

Richardson, K. C. 1947. Contractile tissues in the mammary gland, with special reference to myoepithelium in the goat. Proc. Roy. Soc. B 136:30-45.

Shorten, P. R., I. Vetharaniam, T. K. Soboleva, G. C. Wake, and S. R. Davis. 2002. Influence of milking frequency on mammary gland dynamics. J. Theo. Bio. 218:521-530.

Silanikove, N., A. Shamay, D. Shinder, and A. Moran. 2000. Stress down regulates milk yield in cows by plasmin induced $\beta$-casein product that blocks $\mathrm{K}^{+}$channels on the apical membranes. Life Sciences 67:2201-2212.

Stelwagen, K. 2001. Effect of milking frequency on mammary functioning and shape of the lactation curve. J. Dairy Sci. 84(E Suppl.):E204-E211.

Stelwagen, K., V. C. Farr, S. R. Davis, and C. G. Prosser. 1995a. Time course of milk accumulation-induced opening of mammary tight junctions and blood clearance of milk components. Am. J. Physiol. 269:R848-R855.

Stelwagen, K., V. C. Farr, H. A. McFadden, C. G. Prosser, and S. R. Davis. 1995b. EGTA-induced disruption of epithelial cell tight junctions in the lactating caprine mammary gland. Am. J. Physiol. 273:R379-R386.

Vetharaniam, I., D. G. McCall, P. F. Fennessy, and D. J. Garrick. 2001. A model of mammalian energetics and growth: model development. Agric. Sys. 68(1):55-68.

Weber, A. F., R. L. Kitchell, and J. H. Sauter. 1955. Mammary gland studies. 1 . The identification and characterisation of the smallest lobule unit in the udder of the dairy cow. Am. J. Vet. Res. 16:255-263.

Williams, J. C. 1993. An empirical model for the lactation curve of white British dairy goats. Anim. Prod. 57:91-97.

\section{APPENDIX. Mathematics of the Biology of Senescence}

An alveolus will not exist in a quiescent state for an indefinite length of time, but will become senescent through apoptosis. The time between quiescence and the initition of apoptosis is referred to here as the "duration of quiescence", and will show variance between alveoli. An alveolus which has a duration of quiescence of $\tilde{t}$, and which became quiescent at time $t-\tilde{t}$, would become senescent at time $t$ if it had not been rescued by milking.

After each milking, a fraction $p_{e}$ of queiescent alveoli are emptied and reactivated. Hence, a fraction, $1-p_{e}$, of quiescent alveoli remain engorged after each milking, $i$. Suppose that there were a number of milkings at times $T_{i}$ in the time period $[t-\tilde{t}, t]$. Then of those alveoli with duration of quiescence $\tilde{t}$ which became quiescent at time $t-\tilde{t}$, the fraction which becomes senescent at time $t$ is given by the product of all of the factors ( 1 $p_{e}$ ) for all the milkings $i$, at $T_{i}$, during the time interval from $t-\tilde{t}$ to $t$. This can be represented mathematically as $\prod_{i}\left(1-p_{e}\right)$ for all $i: T_{i} \in[t-\tilde{t}, t]$, where $\prod_{i}$ denotes taking $i$ products.

Let $s(\tilde{t})$ be the probability distribution of the duration of quiescence, $\tilde{t}$, among the alveoli. The rate at which alveoli become quiescent at time $t-\tilde{t}$ is $r_{a q}(t-\tilde{t})$ (Eq. 8 ), and thus the probability of these becoming senescent at time $t$ is

$$
\begin{gathered}
\prod_{i}\left[1-p_{e}\left(u\left(T_{i}-(t-\tilde{t})\right)-\right.\right. \\
\left.\left.u\left(T_{i}-t\right)\right)\right] s(\tilde{t}) r_{a q}(t-\tilde{t})
\end{gathered}
$$

Integrating $\tilde{t}$ over the range 0 to $t$, to account for the distribution, $s(\tilde{t})$, gives:

$$
\begin{gathered}
r_{q s}=\int_{0}^{t} \prod_{i}\left[1-p_{e}\left(u\left(T_{i}-(t-\tilde{t})\right)-u\left(T_{i}\right.\right.\right. \\
-t))] s(\tilde{t}) r_{a q}(t-\tilde{t}) \mathrm{d} \tilde{t}
\end{gathered}
$$

